\title{
Treponema parvum sp. nov., a small, glucuronic or galacturonic acid-dependent oral spirochaete from lesions of human periodontitis and acute necrotizing ulcerative gingivitis
}

\footnotetext{
Institut für Orale Mikrobiologie und Allgemeine Immunologie, Zentrum für Zahn-, Mundund Kieferheilkunde der Universität Zürich, Plattenstrasse 11, $\mathrm{CH}-8028$ Zürich, Switzerland

2 Department of Molecular Genetics, The Forsyth Institute, 140 Fenway, Boston, MA 02115, USA
}

\author{
C. Wyss, ${ }^{1}$ F. E. Dewhirst, ${ }^{2}$ R. Gmür, ${ }^{1}$ T. Thurnheer, ${ }^{1}{ }^{Y}$ Y Xue, ${ }^{1} \dagger$ P. Schüpbach, ${ }^{1}$ \\ B. Guggenheim ${ }^{1}$ and B. J. Paster ${ }^{2}$
}

Author for correspondence: C. Wyss. Tel: +411 634 3322. Fax: +411 6344310. e-mail:wyss.c@zzmk.unizh.ch

Small oral spirochaetes with a strict dependence on either glucuronic acid (GluA) or galacturonic acid (GalA) were isolated from European patients with periodontitis and from Chinese patients with either gingivitis or acute necrotizing ulcerative gingivitis (ANUG). Thirteen such isolates were similar phenotypically to Treponema pectinovorum ATCC $33768^{\top}$ and this classification was confirmed by 165 rRNA sequencing. However, four isolates differed from T. pectinovorum by their small cell size, by a prominent $\beta$-glucuronidase activity, by a distinct protein and antigen profile, by an inability to grow on pectin as sole source of carbohydrate and by a markedly enhanced growth rate when supplied with a second carbohydrate (L-arabinose, D-galactose, D-glucose, D-fructose, D-mannitol, D-mannose, pectin, D-ribose or D-xylose) in addition to the essential GluA/GalA. By 165 rRNA sequencing these four isolates clustered in the recently described phylotype 'Smibert-2'. T. pectinovorum (14 strains) and ' Smibert-2' (four isolates with $\beta$-glucuronidase activity) could each be subdivided into two serotypes based on immunoblot reactivity with two mAbs. Representatives of the two groups, including $T$. pectinovorum ATCC $33768^{\top}$, showed a 1:2:1-type periplasmic flagellar arrangement. 'Smibert-2' is described as a novel species, Treponema parvum sp. nov., with isolate $\mathrm{OMZ}$ $833^{\top}$ ( = ATCC 700770') proposed as the type strain and OMZ 842 (= ATCC 700773) as reference strain for a second serotype.

Keywords: Treponema, oral spirochaetes, periodontitis, ANUG, glucuronidase

\section{INTRODUCTION}

Based on epidemiological studies mainly relying on microscopic evidence spirochaetes are suspected to play an active role in oral disorders ranging from gingivitis and various forms of periodontitis to acute necrotizing ulcerative gingivitis (ANUG). For most of

\footnotetext{
†Present address: Bethune International Peace Hospital, Shijiazhuang People's Republic of China.

Abbreviations: ANUG, acute necrotizing ulcerative gingivitis; GluA, glucuronic acid; GalA, galacturonic acid.

The GenBank accession numbers for the 16S rRNA gene sequences of strains OMZ $833^{\top}$ and OMZ 842 are AF302937 and AF302938, respectively.
}

the more than 40 treponemal phylotypes identified in human oral microbiota, however, little phenotypic information is available. This was recently confirmed even for cultured treponemes present in the Smibert Treponema culture collection (Paster et al., 1998). Although 16S rRNA sequencing identified several novel species, the available phenotypic data were insufficient for their formal taxonomic description (Paster et al., 1998).

Conversely, confident classification of treponemes without recourse to DNA comparison proves difficult not only because these organisms are fastidious in culture but also because standard laboratory methods yield only a very limited number of distinguishing 
characteristics. Consequently, relying only on prominent phenotypic traits, novel isolates may be incorrectly assigned to known species. Relevant examples from our own experience are (1) that cellular fatty acid analysis of human oral treponemes does not always correlate with $16 \mathrm{~S}$ rRNA gene sequence comparative analysis (Paster et al., 1998); (2) the misassignment of strains to the species Treponema denticola based on their strong proteolytic activity (C. Wyss and others, unpublished) and (3) the misassignment of strains to the species Treponema pectinovorum, based on their strict growth dependency on glucuronic acid (GluA)/galacturonic acid (GalA), which is the subject of this study.

The combination of in vitro phenotypic characterization and phylogenetic classification has led recently to the description of four novel oral spirochaetes: Treponema amylovorum (Wyss et al., 1997), Treponema lecithinolyticum (Wyss et al., 1999), Treponema maltophilum (Wyss et al., 1996) and Treponema medium (Umemoto et al., 1997). Speciesspecific or group-specific DNA probes based on characteristics of the respective $16 \mathrm{~S}$ rRNA sequences could be applied to detailed culture-independent epidemiological investigations of the association of different treponemes with various forms of oral disease (Moter et al., 1998; Wyss et al., 1999; Paster et al., 1999).

Here we report that four treponemal isolates in the OMZ (Orale Mikrobiologie Zürich) culture collection cluster within the recently identified species-level phylotype 'Smibert-2' (Paster et al., 1998). Based on the phenotypic characteristics of the OMZ strains we present a formal description of the novel species, for which the name Treponema parvum sp. nov. is proposed, with strain OMZ $833^{\mathrm{T}}\left(=\mathrm{ATCC} 700770^{\mathrm{T}}\right)$ as the designated type strain and OMZ 842 (= ATCC 700773) as reference strain for a second serotype.

\section{METHODS}

Plaque samples. Plaque samples from Swiss $(\mathrm{CH})$ patients with refractory periodontitis were obtained and processed as described by Wyss et al. (1996). Chinese (PRC) patients attending clinics in Beidaihe, Chengede, Shijiazhuang and Xi'an (People's Republic of China) gave informed consent for the collection of plaque and blood samples for use in a scientific study of no direct relevance to their personal treatment. The study group was composed of 21 patients with gingivitis only and 21 patients with all criteria of ANUG, viz. bleeding, fetid odour, punched out interdental papilla, gingival ulceration/necrosis and pseudomembrane (Carranza \& Newman, 1996). The three sites with the most prominent symptoms in each patient were sampled using a sterile curette and pooled into reduced transport fluid (Loesche et al., 1972) supplemented with $10 \%(\mathrm{v} / \mathrm{v})$ glycerol and frozen to $-80^{\circ} \mathrm{C}$ within $1 \mathrm{~h}$ of collection. Frozen samples were transported on dry ice to Zürich and stored there at $-80^{\circ} \mathrm{C}$. After thawing (3-4 months post-collection), samples from eight ANUG and three gingivitis patients were cultured by limit dilution assay in medium OMIZ-Pat with 1\% human serum (OMIZ-Pat/HuS), and rifampicin $\left(1 \mathrm{mg} \mathrm{l}^{-1}\right)$ and fosfomycin $\left(100 \mathrm{mg} \mathrm{l}^{-1}\right)$ as described by Wyss et al. (1997), but additionally supplemented with polymyxin $\left(5 \mathrm{mg} \mathrm{l}^{-1}\right)$ and nalidixic acid $\left(30 \mathrm{mg}^{-1}\right)$. Treponemes isolated by limit dilution culture were cloned on agar plates of OMIZ-Pat/HuS without antibiotics and grown for stock cultures. Strains were characterized as described below. This study was concerned only with clones displaying a strict growth requirement for either GluA or GalA (Table 1).

Phenotypic characterization of bacteria. ApiZym tests, growth assays, electron microscopy and protein, antigen and glycan analyses on blots after SDS-PAGE were performed as described previously (Wyss, 1998; Wyss et al., 1996, 1997, 1999).

For confocal laser scanning microscopy cultures were stained for $15 \mathrm{~min}$ in the dark with Live/Dead BacLight solution $(0.5 \mu \mathrm{l}$ per $25 \mu \mathrm{l}$ culture) (Molecular Probes) and viewed with an Ar-Kr laser (MRL-600; Bio-Rad).

mAbs. mAbs 465TP1 (OMZ 833 ${ }^{\mathrm{T}}$-specific) and 466TP1 (OMZ 881-specific) were produced as described by WernerFelmayer et al. (1988) following the intraperitoneal immunization of a female Balb/c mouse with approximately $10^{8}$ pasteurized $\left(60 \mathrm{~min}\right.$ at $\left.65^{\circ} \mathrm{C}\right) \mathrm{OMZ} 833^{\mathrm{T}}$ and $\mathrm{OMZ} 881$ bacteria. Booster injections were made 4 and 8 weeks after the initial immunization; no adjuvant was used. Supernates of wells with growth of hybrid cells and, later, from culture vessels containing cloned cell lines were screened consecutively by whole-cell ELISA and whole-cell immunofluorescence (Werner-Felmayer et al., 1988). Hybridoma culture supernates diluted 1:10 were used for immunoblots with a second reagent as described by Wyss (1998).

\section{Sequencing of 16S rRNA genes and phylogenetic analysis}

Amplification of genes by PCR and purification of PCR products. The 16S rRNA cistrons were amplified with universal bacterial primers as described previously (Paster et al., 1998). PCR was performed in thin-walled tubes with a Perkin-Elmer 9700 Thermocycler. DNA template $(1 \mu 1$, approx. $100 \mathrm{ng})$ was added to a reaction mixture $(50 \mu \mathrm{l}$ final vol.) containing 20 pmol each primer, $40 \mathrm{nmol}$ dNTPs, 1 unit Taq 2000 polymerase (Stratagene) in buffer containing Taqstart Antibody (Sigma). In a hot-start protocol, samples were preheated at $95^{\circ} \mathrm{C}$ for $8 \mathrm{~min}$ followed by amplification using the following conditions: denaturation at $95^{\circ} \mathrm{C}$ for $45 \mathrm{~s}$, annealing at $60{ }^{\circ} \mathrm{C}$ for $45 \mathrm{~s}$ and elongation for $1.5 \mathrm{~min}$ with an additional $5 \mathrm{~s}$ per cycle. A total of 30 cycles were performed, followed by a final elongation step at $72{ }^{\circ} \mathrm{C}$ for $10 \mathrm{~min}$. The results of PCR amplification were examined by electrophoresis in a $1 \%$ agarose gel. DNA was stained with ethidium bromide and visualized under short-wavelength UV light.

16S rRNA gene sequencing. Purified DNA from PCR was sequenced using an ABI PRISM Cycle-Sequencing kit (BigDye Terminator Cycle Sequencing kit with AmpliTaq DNA polymerase FS; Perkin-Elmer). Primers used for sequencing were as described previously (Dewhirst et al., 1999). Quarter dye chemistry was used with $80 \mu \mathrm{M}$ primers and $1.5 \mu \mathrm{l} \mathrm{PCR}$ product in a final volume of $20 \mu \mathrm{l}$. Cycle sequencing was performed using an ABI 9700 thermocycler with 25 cycles of denaturation at $96^{\circ} \mathrm{C}$ for $10 \mathrm{~s}$, and annealing and extension at $60^{\circ} \mathrm{C}$ for $4 \mathrm{~min}$. Sequencing reactions were run on an ABI 377 DNA sequencer.

$16 \mathrm{~S}$ rRNA data analysis. Sequence data were entered into RNA, a program set for data entry, editing, sequence alignment, secondary structure comparison, similarity 
Table 1. GlyA/GalA-dependent treponemes characterized in this study

\begin{tabular}{|c|c|c|c|c|c|c|c|c|}
\hline Strain & $\begin{array}{c}\text { Other } \\
\text { designation }\end{array}$ & $\begin{array}{c}\text { Patient } \\
\text { age/gender }\end{array}$ & Diagnosis & Country & $\begin{array}{c}\mathrm{mAb} \\
\text { reactivity }\end{array}$ & Classification & $\begin{array}{r}\text { Complete 16S rDNA } \\
\text { sequence accession no. }\end{array}$ & $\begin{array}{l}\text { Other Treponema spp. isolated } \\
\text { from the same sample }\end{array}$ \\
\hline ATCC $33768^{\mathrm{T}}$ & $\begin{array}{l}\text { VPI D-36DR-2; } \\
\text { OMZ } 864\end{array}$ & $? / ?$ & Periodontitis & USA & None & pectinovorum & M71237 & ? \\
\hline OMZ 831 & $32 \mathrm{~A} 1$ & $39 / \mathrm{f}$ & ANUG & PRC & 466 & pectinovorum & AF302940 & parvum, socranskii subsp. socranskii \\
\hline 33R2B & $33 \mathrm{R} 2 \mathrm{~B}$ & $36 / f$ & ANUG & PRC & 466 & pectinovorum & No & denticola, 'vincentii' \\
\hline $34 \mathrm{R} 2 \mathrm{~A}$ & $34 \mathrm{R} 2 \mathrm{~A}$ & $41 / f$ & ANUG & PRC & 466 & pectinovorum & No & denticola, 'vincentii' \\
\hline $35 \mathrm{E} 5 \mathrm{~A}$ & $35 \mathrm{E} 5 \mathrm{~A}$ & $27 / \mathrm{m}$ & ANUG & PRC & 466 & pectinovorum & No & denticola, 'putidum'*, 'vincentii' \\
\hline 36FPA & $36 \mathrm{FPA}$ & $26 / \mathrm{m}$ & ANUG & PRC & 466 & pectinovorum & No & 'putidum'*,'vincentii' \\
\hline 37FPA & 37FPA & $31 / \mathrm{m}$ & ANUG & PRC & None & pectinovorum & No & denticola, 'vincentii', medium \\
\hline 38FPA & $38 \mathrm{FPA}$ & $52 / \mathrm{m}$ & ANUG & $\mathrm{PRC}$ & 466 & pectinovorum & No & $\begin{array}{l}\text { denticola, maltophilum, socranskii subsp. paredis, } \\
\text { 'vincentii' }\end{array}$ \\
\hline 4FP3B & 4FP3B & $40 / \mathrm{m}$ & Gingivitis & PRC & None & pectinovorum & No & 'putidum'* \\
\hline 5FP3D & 5FP3D & $32 / \mathrm{m}$ & Gingivitis & PRC & None & pectinovorum & No & denticola, 'vincentii' \\
\hline 6FP3B & $6 \mathrm{FP} 3 \mathrm{~B}$ & $43 / \mathrm{m}$ & Gingivitis & PRC & None & pectinovorum & No & None \\
\hline KU1A & & Pool & Periodontitis & $\mathrm{CH}$ & None & pectinovorum & No & socranskii 'subsp. 04' \\
\hline OMZ 881 & PF2G & $33 / \mathrm{m}$ & Periodontitis & $\mathrm{CH}$ & 466 & pectinovorum & No & denticola, lecithinolyticum \\
\hline ZA1P & & $35 / \mathrm{m}$ & Periodontitis & $\mathrm{CH}$ & None & pectinovorum & No & socranskii subsp. socranskii \\
\hline OMZ $833^{T}$ & $\begin{array}{l}\text { FO2FA }^{\mathrm{T}} \\
{\text { ATCC } 700770^{\mathrm{T}}}^{\text {ATC }}\end{array}$ & $43 / f$ & Periodontitis & $\mathrm{CH}$ & 465 & 'Smibert-2' & AF302937 & socranskii 'subsp. 04' \\
\hline OMZ 842 & $\begin{array}{l}\text { 31P5C; } \\
\text { ATCC } 700773\end{array}$ & $46 / f$ & ANUG & $\mathrm{PRC}$ & None & 'Smibert-2' & AF302938 & $\begin{array}{l}\text { denticola, socranskii subsp. buccale, socranskii subsp. } \\
\text { paredis, maltophilum, 'vincentii' }\end{array}$ \\
\hline OMZ 832 & $32 \mathrm{CA}$ & $39 / \mathrm{f}$ & ANUG & PRC & None & 'Smibert-2' & AF302941 & pectinovorum, socranskii subsp. socranskii \\
\hline OMZ 843 & $32 \mathrm{COA}$ & $39 / \mathrm{f}$ & ANUG & PRC & None & 'Smibert-2' & AF302939 & pectinovorum, socranskii subsp. socranskii \\
\hline
\end{tabular}

* Novel proteolytic treponeme (C. Wyss and others, unpublished).

matrix generation and dendrogram construction for $16 \mathrm{~S}$ rRNA in Microsoft QuickBasic for use with PCs, and were aligned as described previously (Paster \& Dewhirst, 1988). Our database contains over 3000 sequences obtained in our laboratory and over 1000 obtained from GenBank. Sequences were first checked by BLAST analysis against all entries in GenBank (Altschul et al., 1997). Phylogenetic trees were constructed using the neighbour-joining method of Saitou \& Nei (1987). TREECON, a software package for the Microsoft Windows environment, was used to construct and draw evolutionary trees (Van De Peer \& De Wachter, 1993). Two hundred bootstrap trees were generated and bootstrap confidence levels were determined using the TREECON program.

Nucleotide sequence accession numbers. Accession numbers for complete $16 \mathrm{~S}$ rRNA gene sequences are listed in Table 1.

\section{RESULTS AND DISCUSSION}

Direct methods currently available to examine the potential association of treponemes with different oral diseases include analysis of their distribution by in vitro cultivation, by identification of their $16 \mathrm{~S}$ rRNA signature and by microscopic analysis either directly or in combination with immunolabelling or fluorescent in situ hybridization to phylotype-specific DNA probes; an indirect method is the search for treponeme-specific antibodies in serum or crevicular fluid of the study population. Since each of these methods has inherent limitations conclusive results will depend on their combined application.

All cultivation efforts to date have failed to recover the full spectrum of treponemes present in samples from sites affected with periodontitis, or even to detect reliably the presence of the presently cultivable treponemes. However, cultured treponemes provide the essential material basis for physiological and genomic analysis, as well as for development and validation of culture-independent methods for largescale epidemiological investigations. In our in vitro cultivation of about 150 oral samples from human patients we have focused on a search for isolates with novel characteristics rather than attempting a quantitative analysis of cultivable treponemes. This produced a large collection of cloned treponemal lines which may differ in physiological characters such as growth requirements and enzyme activities or in composition as revealed by protein and antigen pattern or gross cell morphology. The taxonomic weight of these phenotypic characters was not always obvious and classification required the additional analysis of the phylogenetically informative $16 \mathrm{~S}$ rRNA sequences.

\section{Growth characteristics}

In the course of extensive studies of cultivable oral treponemes (Wyss, 1992; Wyss et al., 1996, 1997, 1999) we have isolated 17 distinct clonal lines of spirochaetes with a strict requirement for either GluA or GalA, which is a characteristic of T. pectinovorum (Table 1). T. pectinovorum ATCC $33768^{\mathrm{T}}$ and the 17 isolates listed showed rapid growth and acid production in medium OMIZ-Pat/HuS. However, when single carbohydrates were provided in carbohydrate-free OMIZ-Pat/HuS the growth response of four of these strains (OMZ 833 ${ }^{\mathrm{T}}$, OMZ 832, OMZ 842 and OMZ 843) differed from that of $T$. pectinovorum; i.e. these novel strains showed no growth with pectin and only slow growth with GluA/GalA (GluA being more effective than GalA). In the presence of either GluA or 
GalA growth of these four strains was strongly enhanced by the provision of any one of the following carbohydrates: L-arabinose, D-galactose, D-glucose, D-fructose, D-mannitol, D-mannose, pectin, D-ribose or D-xylose. No effect was seen with: D-arabinose, D-cellobiose, D-fucose, L-fucose, D-GalA, D-GluA, D-lactose, D-maltose, D-melibiose, L-rhamnose, L-sorbose, D-sucrose, D-trehalose and L-xylose. Neither the type strain of $T$. pectinovorum nor any of the other 13 strains showed enhanced growth in any combination of GluA/GalA with a second carbohydrate.

All strains of oral treponemes so far examined grew on medium OMIZ-Pat alone, although addition of $1 \%$ human serum improved the growth of most of them. In contrast, addition of fetal bovine serum (FBS) at concentrations as low as $1 \%(\mathrm{v} / \mathrm{v})$ completely inhibited growth of all isolates of T. amylovorum, $T$. maltophilum, $T$. lecithinolyticum and Treponema socranskii (all subspecies), whereas it promoted growth of $T$. denticola, $T$. pectinovorum, T. medium, 'Treponema vincentii' and the four novel isolates. The metabolic basis of growth stimulation and inhibition of specific Treponema species by human serum and FBS (Wyss, 1992; Wyss et al., 1996, 1997, 1999) is poorly understood but warrants further investigation.

\section{Enzyme activities}

The 19 enzyme activities determined by ApiZym for our 17 treponeme isolates as well as $T$. pectinovorum ATCC $33768^{\mathrm{T}}$ were as follows: low activities of alkaline phosphatase and esterase $\mathrm{C} 4$ and $\mathrm{C} 8$, intermediate activities of acid phosphatase and naphthol phosphohydrolase; other enzyme activities were not detected, except for a strong $\beta$-glucuronidase activity in the novel strains OMZ 832, OMZ 833 ${ }^{\mathrm{T}}$, OMZ 842 and OMZ 843. In contrast to some strains of $T$. pectinovorum studied by Kesavalu et al. (1997), none of our isolates had trypsin-like activity detectable by ApiZym.

\section{Protein and antigen pattern}

The protein patterns revealed a clear difference between the novel strains and the other 13 strains which appeared homogeneous and virtually identical to $T$. pectinovorum ATCC $33768^{\mathrm{T}}$ (Fig. 1a). In contrast to the strains studied by Walker et al. (1997) our $T$. pectinovorum isolates showed no obvious differences in electrophoretic mobility of the major proteins. Such differences, however, were evident in extracts of the four novel isolates; even strains OMZ 832 and $\mathrm{OMZ}$ 843 , isolated from the same patient, showed conspicuously different major protein patterns (Fig. 1a). Furthermore, immunolabelling of such blots revealed two serotypes each within $T$. pectinovorum and the novel isolates: a prominent $\mathrm{mAb} 466$-reactive antigen distributed diffusely over a molecular mass range from about $40>100 \mathrm{kDa}$ was detectable in immunoblots of seven strains (OMZ 831, OMZ 881, 33R2B, 34R2A,

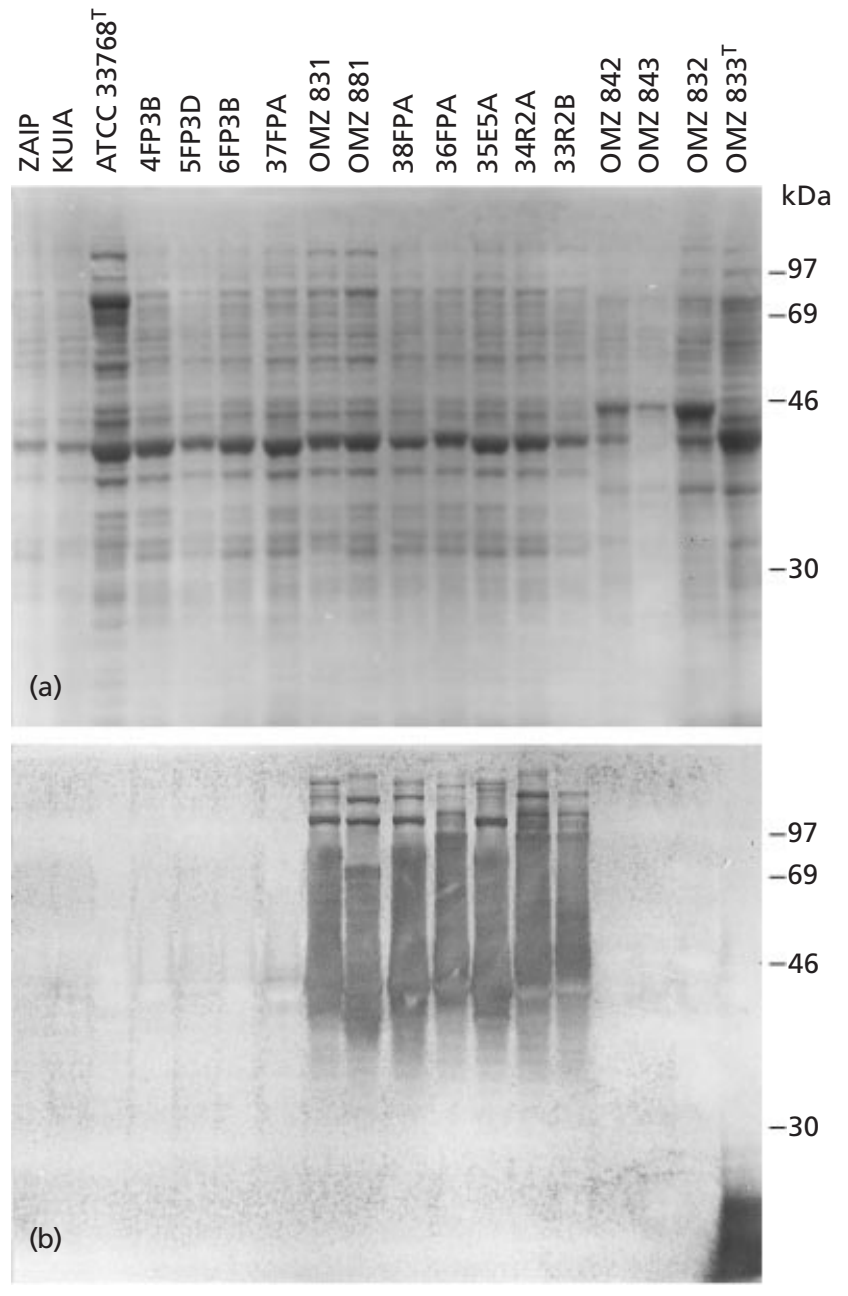

Fig. 1. Protein and antigen pattern of $18 \mathrm{GluA} / \mathrm{GalA}$-dependent oral treponemes after SDS-PAGE and transfer onto nitrocellulose. The first 14 lanes (ZA1P-33R2B) represent clonal lines of $T$. pectinovorum, the four lanes on the right (OMZ $842-\mathrm{OMZ} 833^{\mathrm{T}}$ ) represent the four isolates of $T$. parvum. (a) Blot stained for protein by the reversible copper phthalocyanine tetrasulphonic acid method (Bickar \& Reid, 1992). (b) Same blot immunolabelled with a mixture of mAbs 465TP1 (OMZ $833^{\mathrm{T}}$ specific) and 466TP1 (OMZ 881-specific) after removal of the protein stain. Position of molecular mass markers are indicated on the right.

35E5A, 36FPA, 38FPA), but absent in the seven other isolates and all other cultivable oral spirochaetes. Similarly, a prominent mAb 465 antigen detectable in the $10-20 \mathrm{kDa}$ range was seen in OMZ $833^{\mathrm{T}}$, but not in the other three glucuronidase-active strains (Fig. 1b; Table 1) nor in any other cultured oral spirochaete. The nature of the molecules carrying the epitopes recognized by mAbs 465 and 466 are not known, but may be related to the LPS-like components described by Walker et al. (1999). The pattern of flagellins detected by immunolabelling or by glycan staining in extracts of our 17 isolates were indistinguishable from those previously reported for T. pectinovorum ATCC $33768^{\mathrm{T}}$ (Wyss, 1998) (data not shown). 


\section{Morphology}

Actively proliferating cultures of the novel, $\beta$ glucuronidase-active strains are dominated by thin and very short cells (Fig. 2a), often only one wavelength long, although chain formation occurs frequently in older cultures. Electron microscopic analysis of the novel isolates OMZ $833^{\mathrm{T}}$ and OMZ 842 showed a $1: 2: 1$ flagellar arrangement (Fig. 2b), in accordance with data for one 'Smibert-2' strain of the Smibert collection (Paster et al., 1998). This may appear to distinguish it from T. pectinovorum, which is sometimes cited as having a 2:4:2-type flagellation (Loesche, 1988; Weber \& Canale-Parola, 1984). However, our own electron microscopic analysis of $T$. pectinovorum strains ATCC $33768^{\mathrm{T}}$ and OMZ 831 consistently showed 1:2:1-type flagellation (not shown) and we consider this to be in accordance with the original species description, including the published micrograph (Smibert \& Burmeister, 1983). Confusion may have arisen through verbal descriptions confounding the number of flagella per cell and number of flagella attached per pole. The five pectinolytic spirochaetes characterized by Weber \& Canale-Parola (1984) all show a 1:2:1-type flagellation, which these authors (mistakenly) interpreted to be different from $T$. pectinovorum. At least some of these strains have more recently been classified by $16 \mathrm{~S}$ rRNA sequencing as $T$. pectinovorum (Walker et al., 1997) in spite of significant differences in their $\mathrm{G}+\mathrm{C}$ content, their ability to utilize GalA (Weber \& Canale-Parola, 1984) and their trypsin-like protease activity (Kesavalu et al., 1997).

\section{Phylogenetic classification}

The 16S rRNA sequences of the four GluA/GalAdependent strains with $\beta$-glucuronidase activity (Table 1) were essentially identical to those of the previously identified species-level phylotype 'Smibert-2' (Paster et al., 1998). The 16S rRNA sequences of the five strains, referred to as $T$. parvum in the dendrogram (Fig. 3), differ by only 1-4 bp. T. parvum is the sole representative of Group 7, one of the 10 Groups of oral treponemes previously described (Paster et al., 1998). The closest known relatives of $T$. parvum are $T$. pectinovorum (Group 8) and T. amylovorum (Group 5) at a mean level of $89 \%$ sequence similarity.

\section{Ecology}

The differences in carbohydrate utilization and enzyme activities between $T$. pectinovorum and the four novel strains suggests that these two groups occupy different positions in the oral food chain. However, it appears that the two groups do not exclude each other, since both have been isolated from the same patient (though pooled from three sites). Our novel strains are unable to grow on pectin and are strictly dependent on GluA/GalA. Their strong $\beta$-glucuronidase activity may suffice to procure GluA from an as-yet un-
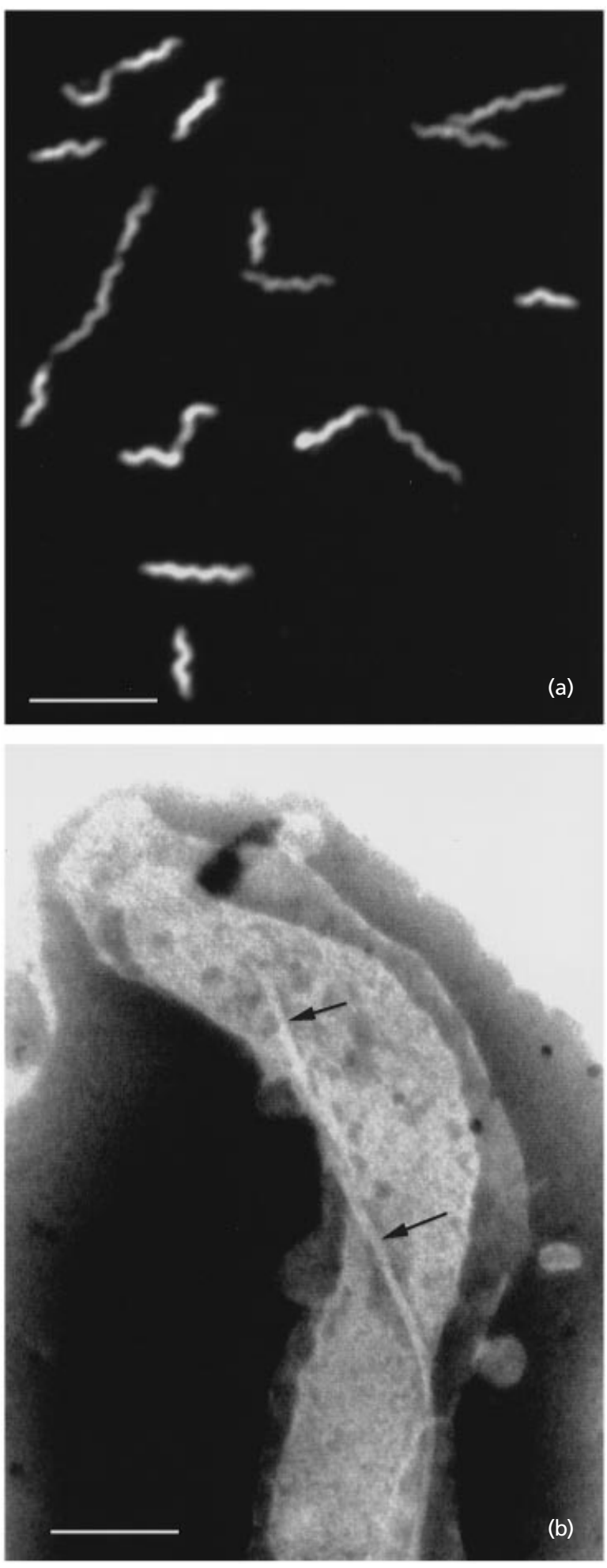

Fig. 2. Morphology of novel GluA/GalA-dependent isolate $O M Z$ $833^{\top}$. (a) Confocal laser scanning microscopic view of Live/Dead BacLight-stained culture. Bar, $2 \mu \mathrm{m}$. (b) Electron micrograph of negatively stained cell pole with one inserted endoflagellum (arrows). Bar, $0.2 \mu \mathrm{m}$.

identified substrate in the oral cavity, e.g. hyaluronic acid and/or chondroitin 4-sulfate. Optimal growth in vitro, however, was dependent on the supply of a 


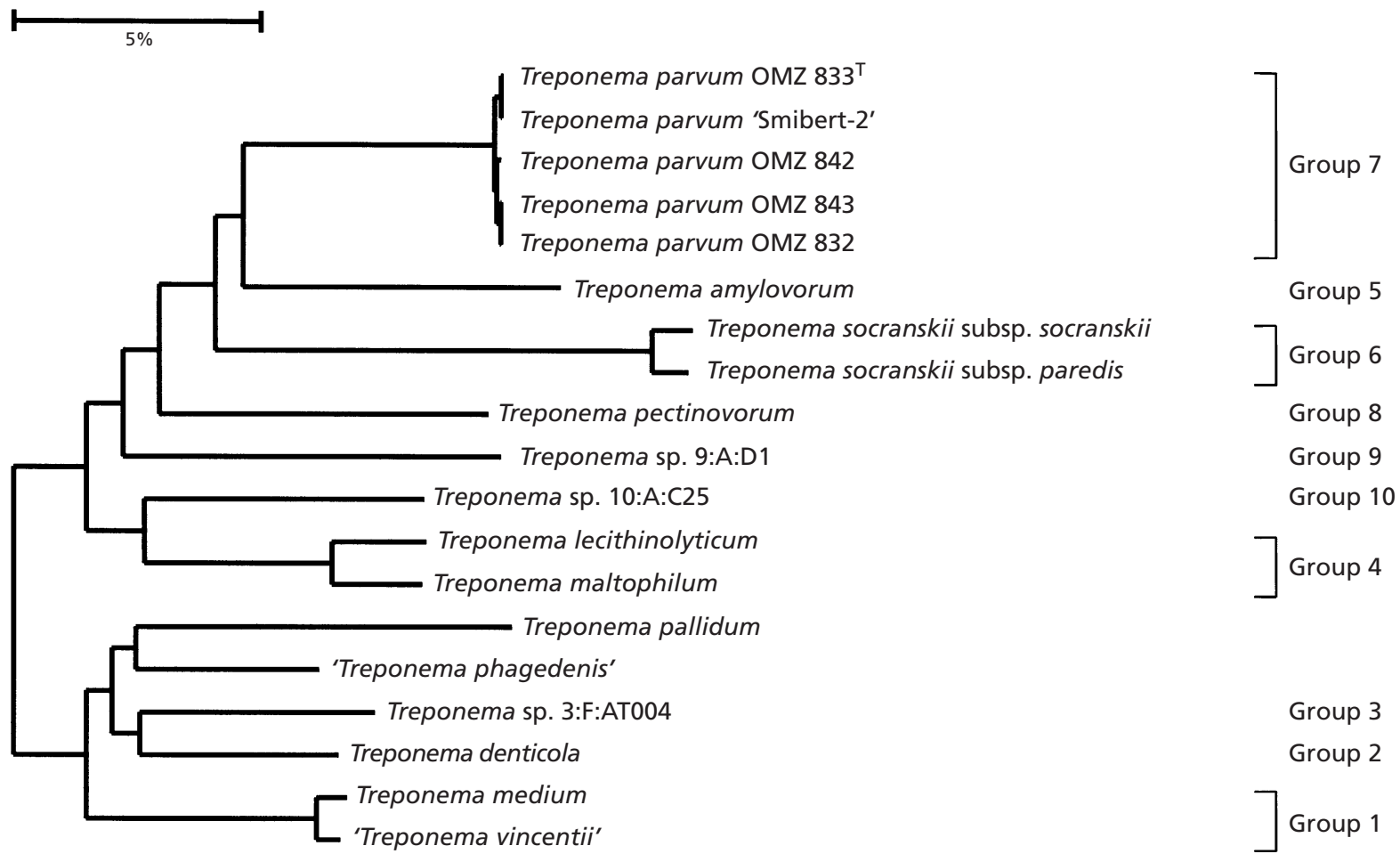

Fig. 3. Phylogenetic position of $T$. parvum. Strains of $T$. parvum form a tight cluster within Group 7 of the oral treponemes, as defined by Dewhirst et al. (2000). Representatives of the other treponemal groups are shown. Marker bar represents a $5 \%$ difference in nucleotide sequences.

second carbohydrate. Since no glycosidase activity other than $\beta$-glucuronidase was detected it is likely that in vivo these organisms depend on degradative activities of other members of the oral microbiota as has been described for other spirochaetes (Glenister et al., 1988; ter Steeg \& van der Hoeven, 1990).

Immunohistochemical analyses of the bacterial populations in ANUG lesions has indicated an increased prevalence of $T$. denticola and of pathogen-related spirochaetes (PROS) (Riviere et al., 1991). Recently, we have shown that PROS are a heterogeneous group of treponemes, including the cultivable ' $T$. vincentii' and T. medium (Wyss, 1998). We have isolated PROS and $T$. denticola as well as numerous other species from Chinese ANUG and gingivitis samples (Table 1). To our knowledge no information concerning $T$. pectinovorum in ANUG has been published. Despite the neglect of quantitative aspects in our cultural studies of oral treponemes it seems noteworthy that $7 / 8$ Chinese ANUG and $3 / 3$ Chinese gingivitis samples, but only $2 />100$ Swiss periodontitis samples yielded typical $T$. pectinovorum. Whether this is a plausible reflection of differences in food consumption between populations in China and Switzerland rather than the state of oral health must be decided by the analysis of adequately matched patient groups. Presently, we are applying phylogenetically discrimi- nating DNA probes to our $21 \mathrm{ANUG}$ and 21 gingivitis samples from Chinese patients to evaluate the distribution of different treponemal phylotypes.

$T$. pectinovorum has been reported to be the only cultivable treponeme with increased frequency during destructive periodontitis (Moore et al., 1991) and to be strongly associated with HIV-associated periodontitis (Walker et al., 1997). In contrast, we have cultured $T$. pectinovorum only from two of more than 100 Swiss periodontitis samples. In a culture-independent epidemiological study a species-specific DNA probe did not detect $T$. pectinovorum in 53 deep periodontal pockets and samples from 44 control sites (Moter et al., 1998). Also, the 16S rRNA sequence library created from a single periodontitis plaque sample (Choi et al., 1994), or from several subjects with ANUG, periodontitis and refractory periodontitis (Dewhirst et al., 2000) did not contain $T$. pectinovorum. These apparently contradictory findings may be attributed to differences in patient populations and in methodology. More conclusive results will depend on the investigation of well characterized patient populations with a combination of available technologies.

\section{Description of Treponema parvum sp. nov.}

Treponema parvum (par.vum. L. neut. adj. parvum small). 
Small, obligately anaerobic, helically coiled, motile treponeme. The cells are approximately $1 \mu \mathrm{m}$ long and $0.18 \mu \mathrm{m}$ wide, with a wavelength of $0.8 \mu \mathrm{m}$ and an amplitude of $0.3 \mu \mathrm{m}$. In rapidly growing cultures cells may be shorter than 1 wavelength but chains of more than 10 wavelengths are also common. Cells contain two periplasmic flagella, one originating at each pole, which overlap in the central region of the cell. In liquid medium undulation, flexing and rotation of cells does not appear to result in directional motility. However, in media of higher viscosity or when cells creep along a surface translational movement is readily detectable. Cells can be stored frozen (liquid nitrogen or mechanical freezer) in OMIZ-Pat/HuS medium supplemented with 10-20\% glycerol. The four isolates OMZ $832,833^{\mathrm{T}}, 842$ and 843 are strictly carbohydratedependent; either GluA or GalA is sufficient for growth, though growth is strongly promoted by addition of any one of the following: L-arabinose, Dgalactose, D-glucose, D-fructose, D-mannitol, D-mannose, pectin, D-ribose or D-xylose. No growth-stimulating effect was seen with D-arabinose, D-cellobiose, D-fucose, L-fucose, D-galacturonic acid, D-glucuronic acid, D-lactose, D-maltose, D-melibiose, L-rhamnose, L-sorbose, D-sucrose, D-trehalose nor L-xylose. The chemically complex (undefined) components of OMIZ-Pat, i.e. YEM (fractionated yeast extract) and DANP (fractionated peptone) (Wyss \& Ermert, 1996), are not strictly required for growth but are strongly stimulatory. Similarly, human serum or FBS are not required but are growth-promoting at $1 \%(\mathrm{v} / \mathrm{v})$. FBS is not inhibitory even at $10 \%(\mathrm{v} / \mathrm{v})$. On OMIZPat/HuS agarose $T$. parvum forms off-white diffuse subsurface colonies up to $3 \mathrm{~mm}$ in diameter after $5 \mathrm{~d}$ of anaerobic incubation at $37^{\circ} \mathrm{C}$. The four OMZ isolates showed uniform reaction in ApiZym tests with weak activities of alkaline phosphatase and esterase $\mathrm{C} 4$ and C8, intermediate activities of acid phosphatase and naphthol phosphohydrolase and strong activity of $\beta$-glucuronidase. The type strain, OMZ $833^{\mathrm{T}}$, was isolated from subgingival plaque of a human deep periodontal lesion and has been deposited at the American Type Culture Collection (ATCC), Manassas, VA, under the accession number ATCC $700770^{\mathrm{T}}$. Strain OMZ 842, isolated from a Chinese ANUG lesions patient, has been deposited at the ATCC under the accession number ATCC 700773 as a reference strain for a serotype distinct from OMZ $833^{\mathrm{T}}$ (no reactivity with $\mathrm{mAb} 465 \mathrm{TP} 1$ ).

\section{Distinguishing characteristics}

The novel isolates show some similarities to $T$. pectinovorum. They are, however, clearly distinguishable phenotypically from this species by the presence of a strong $\beta$-glucuronidase activity, by the inability to utilize pectin as sole source of carbohydrate and by marked differences in protein and antigen pattern revealed by SDS-PAGE. Very short and thin cells also are typical of this novel species, though this is not strongly diagnostic, since all cultured treponemes show variation in morphology under different growth conditions. Our 'Smibert-2' isolates also differ from the $1: 2: 1$ flagellated pectinolytic treponemes isolated from non-human primates by Sela et al. (1987) by virtue of their inability to grow on pectin.

On the basis of $16 \mathrm{~S}$ rRNA sequence comparisons, $T$. parvum differs phylogenetically from other species of Treponema, including $T$. pectinovorum. $T$. parvum is the sole representative of Group 7 of oral Treponema as defined by Paster et al. (1998). The closest relatives of T. parvum are T. pectinovorum ( $88 \%$ similarity) and T. amylovorum ( $90 \%$ similarity).

\section{ACKNOWLEDGEMENTS}

We thank S. Shapiro for critical review of the manuscript, and V. Zängerle and G. Lüönd for expert technical assistance. Supported by NIH grants DE-10374 (to F.E.D) and DE-11443 (to B.J.P) from the National Institute of Dental and Craniofacial Research.

\section{REFERENCES}

Altschul, S. F., Madden, T. L., Schaffer, A. A., Zhang, J., Zhang, Z., Miller, W. \& Lipman, D. J. (1997). Gapped BLAST and PSI-BLAST: a new generation of protein database search programs. Nucleic Acids Res 25, 3389-3402.

Bickar, D. \& Reid, P. D. (1992). A high-affinity protein stain for Western blots, tissue prints, and electrophoretic gels. Anal Biochem 203, 109-115.

Carranza, F. A., Jr \& Newman, M. G. (1996). Clinical Periodontology, 8th edn. Philadelphia, PA: W. B. Saunders.

Choi, B.-K., Paster, B. J., Dewhirst, F. E. \& Göbel, U. B. (1994). Diversity of cultivable and uncultivable oral spirochetes from a patient with severe destructive periodontitis. Infect Immun 62, 1889-1895.

Dewhirst, F. E., Ching, C. C., Paster, B. J., Ericson, R. E., Orcutt, R. P., Schauer, D. B. \& Fox, J. G. (1999). Phylogeny of the defined murine microbiota: altered Schaedler flora. Appl Environ Microbiol 65, 3287-3292.

Dewhirst, F. E., Tamer, M. A., Ericson, R. E., Lau, C. N., Levanos, V. A., Boches, S. K., Galvin, J. L. \& Paster, B. J. (2000). The diversity of periodontal spirochetes by $16 \mathrm{~S}$ rRNA analysis. Oral Microbiol Immunol 15, 196-202.

Glenister, D. A., Salamon, K. E., Smith, K., Beighton, D. \& Keevil, C. W. (1988). Enhanced growth of complex communities of dental plaque bacteria in mucin-limited continuous culture. Microb Ecol Health Dis 1, 31-38.

Kesavalu, L., Ebersole, J. L. \& Holt, S. C. (1997). Virulence characteristics of oral treponemes in a murine model. Infect Immun 65, 5096-5102.

Loesche, W. J. (1988). The role of spirochetes in periodontal disease. Adv Dent Res 2, 275-283.

Loesche, W. J., Hockett, R. N. \& Syed, S. A. (1972). The predominant cultivable flora of tooth surface plaque removed from institutionalized subjects. Arch Oral Biol 17, 1311-1325.

Moore, W. E. C., Moore, L. H., Ranney, R. R., Smibert, R. M., Burmeister, J. A. \& Schenkein, H. A. (1991). The microflora of periodontal sites showing active destructive progression. J Clin Periodontol 18, 729-739.

Moter, A., Hoenig, C., Choi, B.-K., Riep, B. \& Göbel, U. B. (1998). 
Molecular epidemiology of oral treponemes associated with periodontal disease. J Clin Microbiol 36, 1399-1403.

Paster, B. J. \& Dewhirst, F. E. (1988). Phylogeny of Campylobacter, wolinellas, Bacteroides gracilis, and Bacteroides ureolyticus by $16 \mathrm{~S}$ ribosomal ribonucleic acid sequencing. Int $J$ Syst Bacteriol 38, 56-62.

Paster, B. J., Dewhirst, F. E., Coleman, B. C., Lau, C. N. \& Ericson, C. N. (1998). Phylogenetic analysis of cultivable oral treponemes from the Smibert collection. Int J Syst Bacteriol 48, 713-722.

Paster, B. J., Tamer, M. A., Boches, S. K., Galvin, J. L., Lau, C. N., Ericson, C. N. \& Dewhirst, F. E. (1999). Population distribution of cultivable and uncultivable treponemes in periodontal disease (abstract). J Dent Res 78, 504.

Riviere, G. R., Weisz, K. S., Simonson, L. G. \& Lukehart, S. A. (1991). Pathogen-related spirochetes identified within gingival tissue from patients with acute necrotizing ulcerative gingivitis. Infect Immun 59, 2653-2657.

Saitou, N. \& Nei, M. (1987). The neighbor-joining method: a new method for reconstructing phylogenetic trees. Mol Biol Evol 4, 406-425.

Sela, M. N., Kornman, K. S., Ebersole, J. L. \& Holt, S. C. (1987). Characterization of treponemes isolated from human and nonhuman primate periodontal pockets. Oral Microbiol Immunol 2 , 21-29.

Smibert, R. M. \& Burmeister, J. A. (1983). Treponema pectinovorum sp. nov. isolated from humans with periodontitis. Int $J$ Syst Bacteriol 33, 852-856.

ter Steeg, P. F. \& van der Hoeven, J. S. (1990). Growth stimulation of Treponema denticola by periodontal microorganisms. Antonie Leeuwenhoek 57, 63-70.

Umemoto, T., Nakazawa, F., Hoshino, E., Okada, K., Fukunaga, M. \& Namikawa, I. (1997). Treponema medium sp. nov., isolated from human subgingival dental plaque. Int J Syst Bacteriol $\mathbf{4 7}$, 67-72.

Van De Peer, Y. \& De Wachter, R. (1993). TREECON: a software package for the construction and drawing of evolutionary trees. Comput Applic Biosci 9, 177-182.
Walker, S. G., Ebersole, J. L. \& Holt, S. C. (1997). Identification, isolation, and characterization of the 42-kilodalton major outer membrane protein (MompA) from Treponema pectinovorum ATCC 33768. J Bacteriol 179, 6441-6447.

Walker, S. G., Xu, X., Altman, E., Davis, K. J., Ebersole, J. L. \& Holt, S. C. (1999). Isolation and chemical analysis of a lipopolysaccharide from the outer membrane of the oral anaerobic spirochete Treponema pectinovorum. Oral Microbiol Immunol 14, 304-308.

Weber, F. H. \& Canale-Parola, E. (1984). Pectinolytic enzymes of oral spirochetes from humans. Appl Environ Microbiol 48, 61-67.

Werner-Felmayer, G., Guggenheim, B. \& Gmür, R. (1988). Production and characterization of monoclonal antibodies against Bacteroides forsythus and Wolinella recta. J Dent Res 67, 548-553.

Wyss, C. (1992). Growth of Porphyromonas gingivalis, Treponema denticola, $T$. pectinovorum, T. socranskii, and $T$. vincentii in a chemically defined medium. J Clin Microbiol 30, 2225-2229.

Wyss, C. (1998). Flagellins, but not endoflagellar sheath proteins, of Treponema pallidum and of Pathogen-Related Oral Spirochetes are glycosylated. Infect Immun 66, 5751-5754.

Wyss, C. \& Ermert, P. (1996). Borrelia burgdorferi is an adenine and spermidine auxotroph. Microb Ecol Health Dis 9, 181-185.

Wyss, C., Choi, B.-K., Schüpbach, P., Guggenheim, B. \& Göbel, U. B. (1996). Treponema maltophilum sp. nov., a small oral spirochete isolated from human periodontal lesions. Int J Syst Bacteriol 46, 745-752.

Wyss, C., Choi, B.-K., Schüpbach, P., Guggenheim, B. \& Göbel, U. B. (1997). Treponema amylovorum sp. nov., a saccharolytic spirochete of medium size isolated from an advanced human periodontal lesion. Int $J$ Syst Bacteriol 47, 842-845.

Wyss, C., Choi, B.-K., Schüpbach, P., Moter, A., Guggenheim, B. \& Göbel, U. B. (1999). Treponema lecithinolyticum sp. nov., a small, saccharolytic spirochaete with phospholipase $\mathrm{A}$ and $\mathrm{C}$ activities associated with periodontal diseases. Int J Syst Bacteriol 49, $1329-1339$. 